\title{
Odontossecção Intermediária em Retenção Atípica de Caninos Inferiores
}

\author{
Intermediate Tooth Section Tecnique in \\ Atipicaly Retained Lower Canine
}

Taís Weber Furlanetto de Azambuja*

Francesca Bercini **

RESUMO

Dalva Maria Pereira Padilha***

As autoras relatam caso de remoção cirúrgica de dois caninos inferiores retidos horizontalmente na região anterior do mento. Foi utilizada a técnica de odontossecção intermediária para remoção destas peças dentárias com o objetivo de minimizar a ostectomia. A odontossecção intermediária permitiu a remoção das porções centrais, coronárias e apicais dos dentes através de uma abertura óssea pouco extensa.

UNITERMOS

Dente retido, técnica cirúrgica, odontossecção.

\section{INTRODUÇÃO}

Dente incluso é para Graziani ${ }^{1}$ um órgão dentário que, mesmo completamente desenvolvido, não fez sua erupção na época normal. Classifica de inclusão intra-óssea quando o dente estiver no interior do osso; inclusão submucosa quando recoberto por fibromucosa e semi-incluso, quando o dente venceu a camada fibromucosa, porém não terminou sua erupção.

\section{REVISÃO DE LITERATURA}

A terminologia empregada para as retenções dentárias é variada provocando controvérsias. Archer ${ }^{2}$ denomina esta anomalia como dente impactado e Ries Centeno ${ }^{14}$ como dente retido, o que nos parece mais apropriado.

$\mathrm{Na}$ prática odontológica a retenção dentária é freqüentemente encontrada. Os dentes que mais comumente sofrem retenção nos adultos e adolescentes são os terceiros molares. Nas crianças, porém são os caninos superiores.

Para Dachi e Howell ${ }^{3}$ os dentes mais freqüentemente retidos são os terceiros molares superiores seguidos dos terceiros molares inferiores, caninos superiores e pré-molares inferiores. Num estudo de 1685 radiografias constataram que, em 281 destas (16,7\%) havia a presença de no mínimo um dente retido. Encontraram retidos 213 terceiros molares superiores, 209 terceiros molares inferiores e 28 caninos superiores. Opinião semelhante a respeito da freqüência de retenção tem Petersen ${ }^{11}$.

Kramer e Williams ${ }^{6}$ concordam com esta ordem, porém eles apontam o segundo molar em quarto lugar de freqüência de retenção, seguido dos pré-molares. Estes autores analisando a incidência de dentes retidos em 3745 radiografias, encontraram em 681,59 destas $(18,2 \%)$ um ou mais dentes retidos. A retenção dentária foi identificada em 45 caninos superiores (3,69\%), 3 caninos inferiores $(0,24 \%), 717$ terceiros molares superiores $(58,87 \%)$ e 429 terceiros molares inferiores $(35,22 \%)$, num total de 1218 retenções.

Grover e Lorton ${ }^{5}$ encontraram a seguinte seqüência de retenção: terceiros molares superiores, terceiros molares inferiores, caninos superiores, pré-molares inferiores e caninos inferiores. No estudo de 5000 radiografias observaram 10979 dentes retidos, sendo 5770 terceiros molares superiores (52,56\%), 4984 terceiros molares inferiores $(45,40 \%), 142$ caninos superiores $(1,29 \%)$ e 11 caninos inferiores $(0,10 \%)$.

Rohrer ${ }^{15}$ na análise de 3000 radiografias, encontrou retidos 62 caninos superiores $(2,06 \%)$ e 3 caninos inferiores $(0,1 \%)$.

Miranti e Levbarg ${ }^{8}$ num levantamento de 2000 radiografias encontraram a ocorrência de canino inferior retido em $0,05 \%$.

As técnicas cirúrgicas utilizadas para o tratamento das retençōes dentárias são divididas em dois grupos: conservador, que visa a manutenção da peça dentária e radical, que consiste na remoção cirúrgica do dente retido.

Segundo a literatura, o tratamento cirúrgico conservador de um dente retido visa a exposição cirúrgica da sua coroa na expectativa de sua erupção. Quando há previsão de que a erupção livre não aconteça, a tração ortodôntica para movimentação do dente será necessária. Laçada de fio metálico na coroa dentária (em desuso), perfuração da coroa com passagem de fio e colagem de bracket na coroa são alternativas para tracionamento do dente. ${ }^{1,2,9,13,14}$
Quando existe a impossibilidade de tratamento conservador a cirurgia radical é necessária na quase totalidade dos casos. Petersen ${ }^{11}$ estabelece indicações e contra-indicações para a remoção de dentes impactados. As indicações compreendem a prevenção da doença periodontal, da cárie dentária, da pericoronarite, da reabsorção radicular, de cistos e tumores, da dor de origem desconhecida e da fratura de mandíbula, além de dentes impactados sob próteses, facilitação do tratamento ortodôntico e otimização da saúde periodontal. As contraindicações dizem respeito aos extremos de idade, à condição médica comprometida e a possibilidade de dano excessivo às estruturas subjacentes.

Há concordância entre os autores de que o tratamento cirúrgico para os dentes retidos exige um detalhado exame clínico e radiográfico além de um plano cirúrgico correto que compreende, basicamente, a incisão, o descolamento do retalho muco-periósteo, a ostectomia e/ou odontossecção.

Miranti e Levbarg ${ }^{8}$ apresentaram caso de remoção cirúrgica de canino inferior retido horizontal. O dente apresentava-se invertido, ou seja, a coroa apontava para o bordo lingual da mandibula. A incisão intra-oral foi aplicada e as técnicas de ostectomia e odontossecção foram utilizadas.

Milano, Barrett e Marshall ${ }^{7}$ relataram caso de retenção de canino inferior localizado abaixo dos ápices dos dentes ântero-inferiores, em que foi removida uma porção óssea intermediária, na porção mentoniana, juntamente com o dente. Foram fixadas duas placas de titânio, em forma de X, para evitar fratura óssea. \footnotetext{
* Professora Adjunta das Disciplinas de Anestesiologia e Exodontia e Exodontia II da FO/UFRGS. Especialista em Educação, Mestre em Cirurgia e
Traumatologia Bucomaxilofacial

** Professora Assistente das Disciplinas de Anestesiologia e Exodontia e Exodontia II da FO/UFRGS. Mestre em Cirurgia e Traumatologia Bucomaxilofacial.

*** Professora Adjunta da Disciplina de Exodontia II da FO/UFRGS. Especialista em Educaçāo, Mestre em Traumatologia Bucomaxilofacial e Doutora em Estomatologia.
} 
Prabhu e Munshi12 propuseram hemissecçāo do primeiro molar inferior permanente, com remoção da raiz mesial, para obter espaço para a erupção do segundo pré-molar inferior retido, em posiçāo vertical.

Enquanto a hemissecção é a divisão da peça dentária, com remoção de parte do dente ou de uma ou mais raízes, consideradas inaproveitáveis, a odontossecção consiste em secionar o dente em partes, com objetivo de facilitar a exodontia, removendo as raízes individualmente.

Segundo Graziani ${ }^{4}$ um dos princípios da cirurgia das retençōes dentárias é a necessidade de fazer-se uma abertura óssea suficientemente ampla para permitir a passagem do maior diâmetro do dente retido. Portanto, diminuindose o tamanho do dente reduzimos automaticamente a extensão da ressecção óssea e, por conseguinte, o trauma operatório.

Archer ${ }^{2}$ recomenda a técnica de odontossecção no tratamento cirúrgico de dentes retidos, associando cortes perpendiculares e paralelos ao longo eixo dos dentes em casos de molares inferiores retidos horizontais.

Ries Centeno ${ }^{14}$ indica a técnica de odontossecção para remoção cirúrgica de caninos e pré-molares superiores retidos horizontais, com ostectomia para acessar a coroa e a porção cervical da raiz. O primeiro corte, no colo dentário, tem por objetivo separar a coroa da raiz, que é o primeiro segmento a ser removido. A raizé trazida para o interior da cavidade vazia deixada pela coroa e faz-se o segundo corte para remover uma porção intermediária do dente, ou seja, o terço médio radicular. Por último, traciona-se e remove-se a porção radicular apical.

O objetivo deste trabalho é apresentar a técnica cirúrgica de odontossecção intermediária utilizada na remoção de dentes retidos em posição atípica.

\section{CASO CLÍNICO: CANINOS INFERIORES}

A Paciente C. D., 19 anos, sexo feminino, raça branca, foi encaminhada para tratamento radical de caninos retidos por indicação ortodôntica.

Ao exame clínico foi verificada a ausência dos caninos inferiores ( 43 e 33 ) e ao exame radiográfico (Fig. 1), constatada a retenção intraóssea destes, bilateralmente. Os caninos apresentavam-se em posição horizontal, pelo lado vestibular, com suas coroas aproximando-se na linha média, na região anterior e com os ápices voltados para distal, na regiāo de forames mentonianos. Estes dentes estavam localizados entre os ápices radiculares dos dentes ânteroinferiores e o bordo da mandíbula, na região do mento. De acordo com Ries Centeno ${ }^{14}$ estes caninos são classificados como Classe III ( Dentado, Bilateral ); b (vestibular); bl ( posição horizontal ).

O procedimento cirúrgico constou de anestesia regional dos nervos Dentário Inferior, Lingual e Bucinador do lado direito e, do lado esquerdo, anestesia do nervo Incisivo e anestesias terminais por lingual. A incisão realizada foi a de Newmann seguida de descolamento do retalho muco-periósteo.

Através de ostectomia sobre a cortical óssea vestibular obtivemos acesso ao canino do lado direito em suas porçōes cervical e mediana da raiz . A porção coronária não foi totalmente exposta pela ostectomia no sentido de preservar ao máximo o tecido ósseo. Nesse momento, procedeu-se a odontosseç̧ào intermediária, na metade da raiz, no sentido de remover uma fatia central do dente, ou seja, o seu terço médio entre o ápice e a coroa. (Fig. 2). Uma vez removida a porção mediana, procedeu-se a avulsão da porção apical e coronária. Esta mesma técnica de odontossecção intermediária foi utilizada também para a exodontia do canino do lado esquerdo. (Fig. 3). Os cuidados com a cavidade óssea, sutura e pós-operatónio foram as de rotina.

\section{DISCUSSĀO}

A odontossecção visa facilitar a remoção de uma peça dentária através da diminuição das áreas e zonas retentivas do próprio dente através da sua fragmentação bem como a preservação de tecido ósseo hígido e que, em algumas circunstâncias protege regiōes e estruturas ósseas anatômicas, esteticamente importantes como neste caso de caninos retidos na região do mento.

Milano, Barrett e Marshall ${ }^{7}$ descreveram um caso em que este princípio de preservação estética de tecido ósseo não foi observado, pois para remoção de um canino na regiāo do mento, um grande segmento ósseo foi removido.

Por outro lado, Graziani ${ }^{4}$ aponta a necessidade de abertura ampla o suficiente do tecido ósseo para permitir a passagem do maior diâmetro dentário. Esta técnica não observa, entretanto, o princípio de fragmentação e remoção do tecido dentário em detrimento de uma abertura mais conservadora da estrutura óssea.

Na técnica preconizado por Ries Centeno ${ }^{14}$ para remoção cinúrgica de caninos horizontais a ostectomia engloba a totalidade da coroa e região cervical do dente a ser removido configurando também um desnecessário sacrifício do tecido ósseo em relação ao benefício resultante do seccionamento dentário.

Portanto, no caso ora descrito, ao ser preconizada a odontossecção intermediária, o princípio de preservação do tecido ósseo é alcançado através da manutenção da continuidade óssea importante para a perfeita recuperação estética e funcional das regiōes atingidas.

\section{SUMMARY}

Two lower canines horizontally situated in the anterior mental region were removed. In order to minimize bone loss during teeth extraction it was used an intermediate tooth section technique. Sectioning allows central, crown and apical portions of the tooth to be removed through a not too lange opening provided by bone removal.

\section{KEYWORDS} division.

Impacted tooth, surgical technique, tooth

\section{REFERÊNCIAS BIBLIOGRÁFICAS}

1. ALMEIDA, F. L. D. et al. Caninos Inclusos e Impactados: abordagem ortocirúrgica. Rev. Bras. Odontol., Rio de Janeiro, v. 52, n. 5, p. $50-53$. set/out., 1995.

2. ARCHER, W. H. Oral and Maxillofacial Surgery. 5.ed. Philadelphia: Saunders, 1975

3. DACHI; S. F. HOWELL, F. V. A Survey of 3.874 Routine Full-Mouth Radiographs. II A study of impacted teeth. Oral Surg. Oral Pathol. Oral Med., St. Louis, v. 14, n. 10, p. 1165-1169, Oct. 1961 .

4. GRAZIANI, M. Cirurgia Bucomaxilofacial. 8.ed. Rio de Janeiro: Guanabara Koogan, 1995.618 p.

5. GROVER, P S \& LORTON, L The Incidence of Unerupted Permanent Teeth and Related Clinical cases. Oral Surg. Oral Med., Oral Pathol., St Louis, v. 59, n. 4, p. $420-425$, Apr. 1985.

6. KRAMER, R. M. WILLIAMS, A. C. The Incidence of Impacted Teeth: a survey at Harlem hospital. Oral Surg. Oral Med., Oral Pathol., St. Louis, v. 29 n. 2, p. $237-241$, Jan /Jun., 1970.

7. MILANO, M.; BARRETT, L; MARSHALL, E. Extraction of a Horizontally Impacted Mandibular Canine Through a Genioplasty Aproach: report of a case. J. Oral Maxillofac. Surg., Philadelphia, v. 54, n. 10 , p. $1240-1242$, Oct. 1996

8. MIRANTI, R. LEVBARG, M. Extraction of a Horizontally Transmigrated Impacted Mandibular Canine: Report of a case. J. Am. Dent. Assoc. Chicago v. 88, p. $607-610$, Mar. 1974.

9. PATRIKIOU A K \& KATSAVRIAS, E. G Repositioning Ankylosed Maxillary Canines by Segmental Osteotomy, J. Clin. Orthod., Boulder v. 29 , n. 10 , p. $625 \cdot 628$, Oct. 1995 .

10. PELL, G. J. \& GREGORY, G. T. Report on a Ten-Year Study of a Tooth Division Technique for the Removal of Impacted Teeth. Am. J. Orthod. Ora Surg., St. Louis, v. 28, n. 1 1, p. $660-666$, Nov 1942.

11. PETERSON, L. J. et al. Cirurgia Oral e Maxilofacial Contemporânea. 2. ed. Rio de Janeiro: Guanabara Koogan, 1986.702 p.

12. PRADHU, N. T MUNSHI, A. K. Hemisection of a Permanent Mandibular First Molar: a treatment option for a vertically impacted second premolar. J. Clin. Pediatr. Dent., Birmingham, v. 20, n. 3, p $233-235,1996$

13. PURICELLI, E. Tratamento de Caninos Retidos pela Apicotomia. Rev. Gaucho Odotol., Porto Alegre, v. 35, n. 4 , p. $326 \cdot 330$, jul./ago. , 1987.

14. RIES CENTENO, G. A. Cirurgia Bucal. Con Patologia, Clínica e Terapeutica. 8. ed. Buenos Aires: El Ateneo, $1979.680 \mathrm{p}$

15. RÖHRER, A. Displaced and Impacted Canines. Int. J. Orthod. Oral .Surg., v. 15, p. 1002, 1929. 


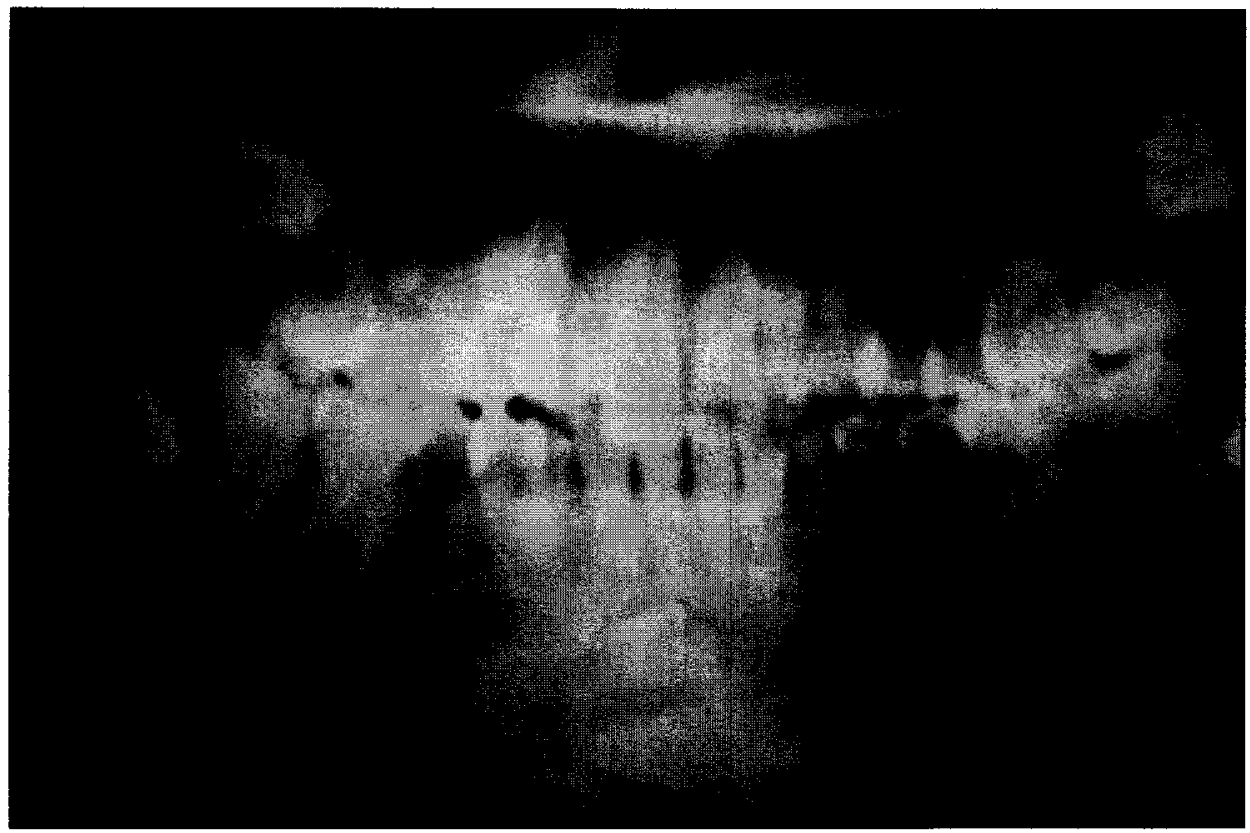

Figura $l$ - Radiografia panorâmica $\mathrm{p}$ operatória

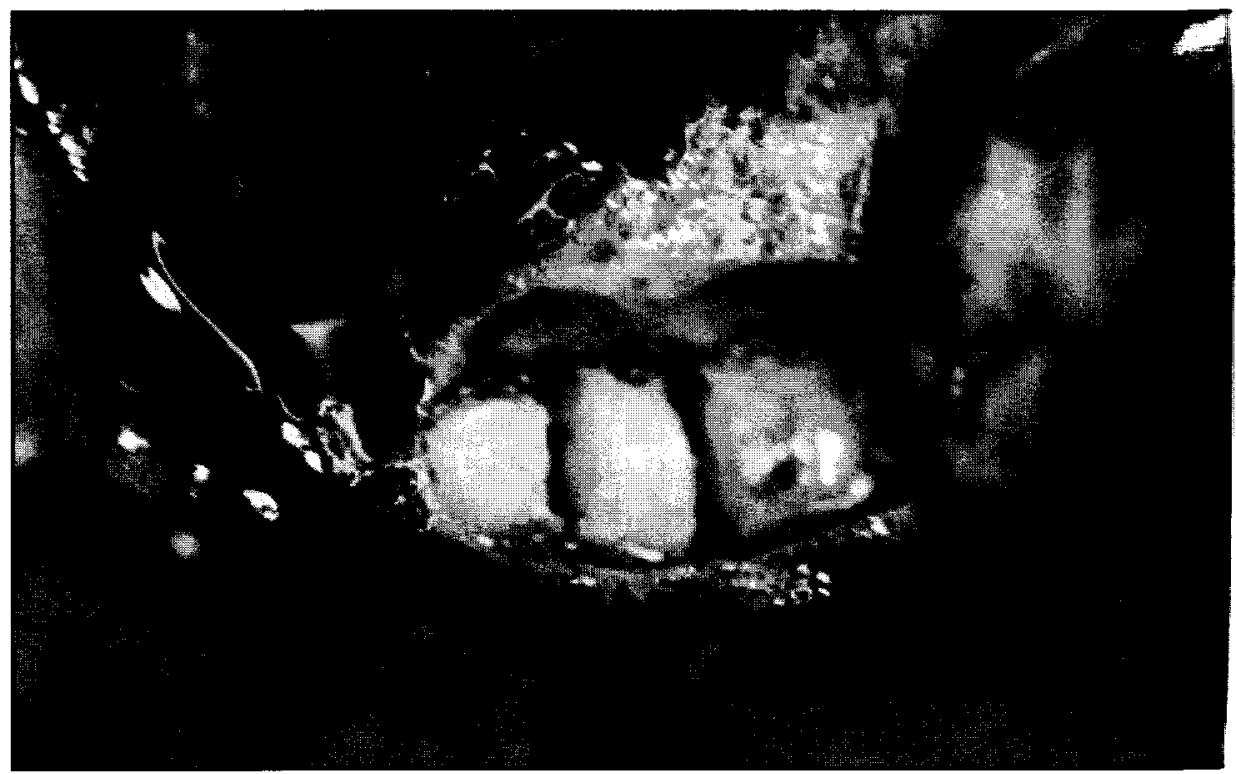

Figura 2 - Aspecto trans-operatório: odontossecção intermediária

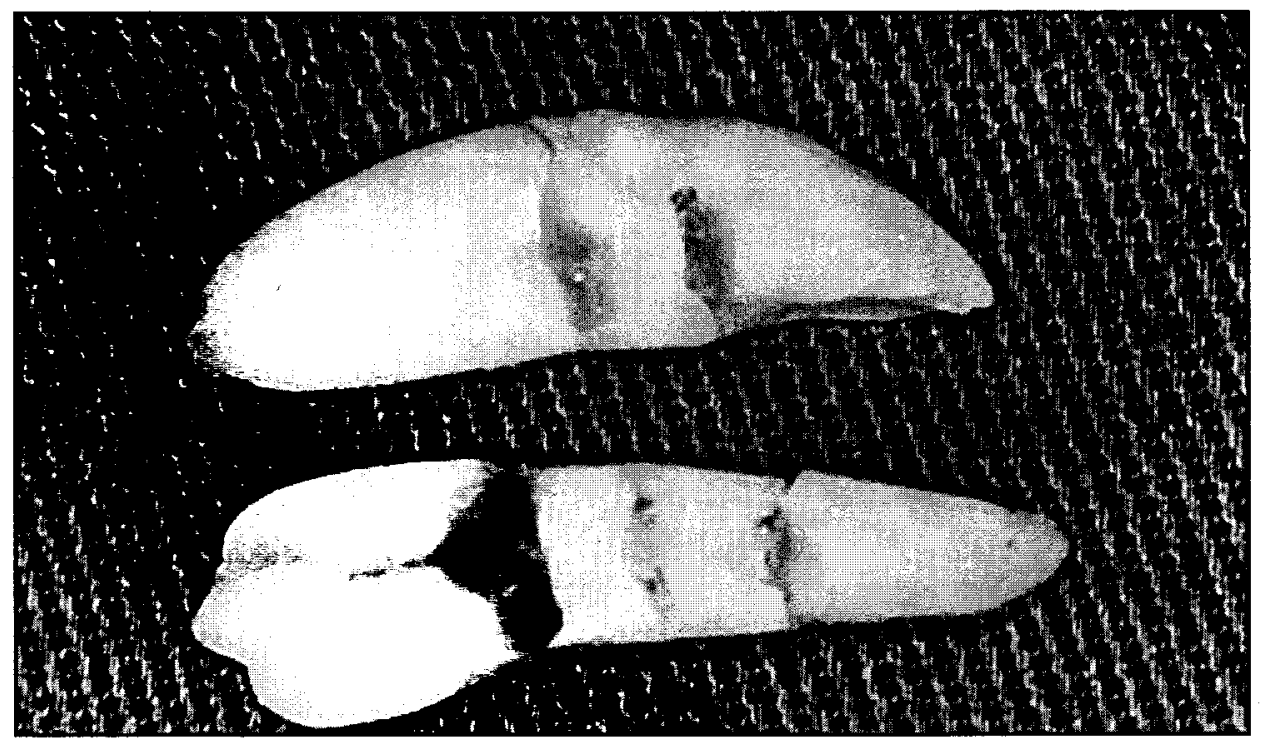

Figura 3 - Aspecto do dente seccionado R. Fac. Odontol., Porto Alegre, v. 40, n. I, p. 46-49, s: :- 